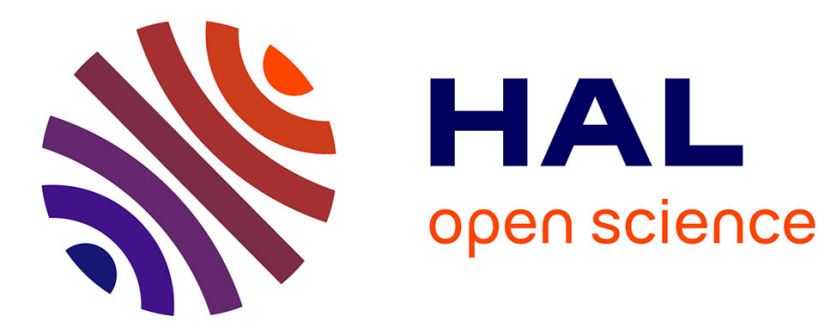

\title{
Fault-Tolerant Operation of an Open-End Winding Five-Phase PMSM Drive with Inverter Faults
}

Fabien Meinguet, Ngac-Ky Nguyen, Paul Sandulescu, Xavier Kestelyn, Eric Semail

\section{- To cite this version:}

Fabien Meinguet, Ngac-Ky Nguyen, Paul Sandulescu, Xavier Kestelyn, Eric Semail. Fault-Tolerant Operation of an Open-End Winding Five-Phase PMSM Drive with Inverter Faults. IECON 39th Annual Conference of the IEEE Industrial Electronics Society, Dec 2013, Austria. p1-7. hal-00876144

\author{
HAL Id: hal-00876144 \\ https://hal.science/hal-00876144
}

Submitted on 24 Oct 2013

HAL is a multi-disciplinary open access archive for the deposit and dissemination of scientific research documents, whether they are published or not. The documents may come from teaching and research institutions in France or abroad, or from public or private research centers.
L'archive ouverte pluridisciplinaire HAL, est destinée au dépôt et à la diffusion de documents scientifiques de niveau recherche, publiés ou non, émanant des établissements d'enseignement et de recherche français ou étrangers, des laboratoires publics ou privés. 


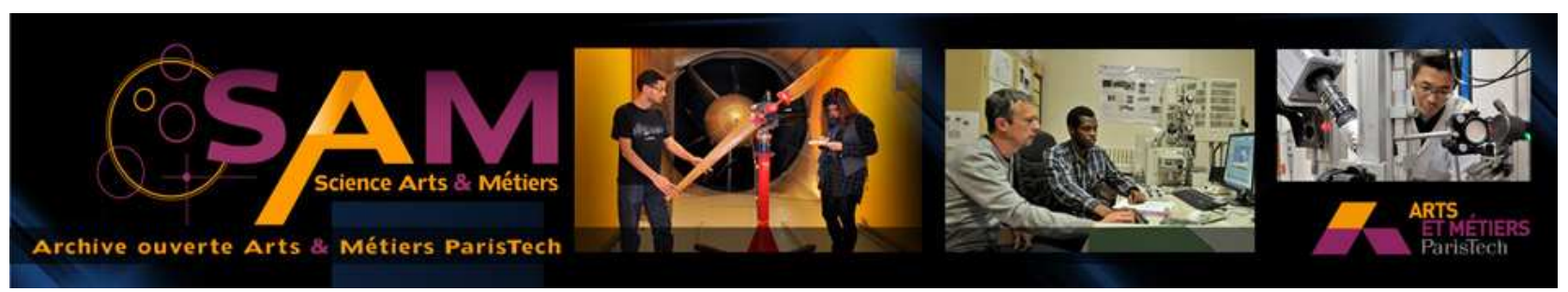

Science Arts \& Métiers (SAM)

is an open access repository that collects the work of Arts et Métiers ParisTech researchers and makes it freely available over the web where possible.

This is an author-deposited version published in: http://sam.ensam.eu

Handle ID: .http://hdl.handle.net/10985/7421

\section{To cite this version :}

Fabien MEINGUET, Ngac-ky NGUYEN, Paul SANDULESCU, Xavier KESTELYN, Eric SEMAIL Fault-Tolerant Operation of an Open-End Winding Five-Phase PMSM Drive with Inverter Faults $-2013$ 


\title{
Fault-Tolerant Operation of an Open-End Winding Five-Phase PMSM Drive with Inverter Faults
}

\author{
Fabien Meinguet, Ngac-Ky Nguyen, Paul Sandulescu, Xavier Kestelyn, Eric Semail \\ Laboratory of electrical engineering and power electronics \\ Art et Métiers ParisTech \\ Lille, France \\ eric.semail@ensam.eu
}

\begin{abstract}
Multi-phase machines are known for their faulttolerant capability. However, star-connected machines have no fault tolerance to inverter switch short-circuit fault. This paper investigates the fault-tolerant operation of an open-end fivephase drive, i.e. a multi-phase machine fed with a dual-inverter supply. Open-circuit faults and inverter switch short-circuit faults are considered and handled with various degrees of reconfiguration. Theoretical developments and experimental results validate the proposed strategies.
\end{abstract}

Keywords-AC drives, Control reconfiguration, Fault tolerance, Multi-phase machines, Open-end winding, PMSM, Reliability.

\section{INTRODUCTION}

Reliability of drives is a key parameter in some critical applications and its improvements can be obtained in various ways. With a conservative design, the system is operated well below its rated value, and therefore its expected lifetime increases. However, in this case, system efficiency may be reduced and the system may not be able to withstand sporadic faults. This is particularly true for power electronics components, of which failures are yet mostly unpredictable [1].

To increase the drive availability, fault tolerance has been introduced in the last decades. Fault tolerance can be applied to the inverter [2-6] and/or to the electric machine [7-10]. Specific configurations of three-phase and multi-phase drives have been investigated for their properties in healthy and faulty conditions.

Multi-phase drives have additional degrees of freedom compared with three-phase machines. These degrees of freedom can be used for different purposes, such as additional torque generation or fault tolerance when a part of the system fails. Fault detection and control reconfiguration of the drive in case of open-circuit faults have been extensively studied in the past years [11-16]. On the other hand, only a few works have addressed the problem of inverter switch short-circuit faults [6], except in topologies with additional components such as fuses and parallel thyristors which are not used in healthy operation [2-5].

In [6], the authors investigate a three-phase drive topology with an open-end winding machine and a dual-inverter supply. The authors show that fault tolerance against open-circuit fault

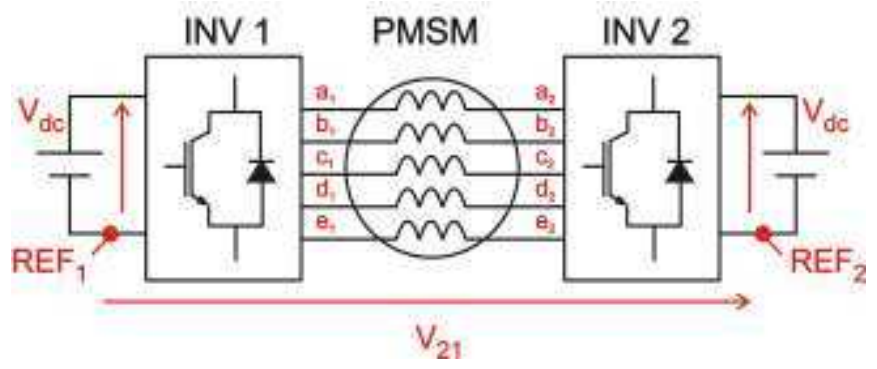

Fig. 1: Drive topology

requires a zero-sequence path for the current (connection between both inverters). On the other hand, inverter switch short-circuit faults can be handled by creating an artificial neutral point through the faulty inverter. In the latter case, this reconfiguration cannot be applied if there is a zero-sequence path. Therefore, a complete fault tolerance cannot be achieved without additional devices which connect or disconnect both inverters depending on the drive condition.

These issues can be solved with an open-end five-phase drive since the machine can be operated with open-circuit faults without zero-sequence path. This topology is illustrated in Fig. 1. This topology has already been investigated in [12] where the authors propose a space vector modulation technique.

In the present paper, the fault-tolerant capability of an openend winding five-phase PMSM drive is studied. Various degrees of reconfiguration are investigated, starting from no reconfiguration up to a full reconfiguration (control algorithm and gate signals).

It is assumed that the inverter is equipped with smart drivers, which are able to locate a short-circuit fault almost instantaneously and to remove the gate signal of the complementary switch to avoid a short-circuit of the DC source.

In section II, the drive modeling is presented, highlighting the zero-sequence component which is paramount for control reconfiguration. In section III, a simple modulation strategy and the control algorithms are presented for the healthy and faulty conditions. Inverter switch short-circuit faults are addressed in detail, while open-circuit faults are briefly addressed as well. Finally, the test bed is presented in section IV and experimental results validate the theoretical part. Section $\mathrm{V}$ ends the paper by a conclusion. 

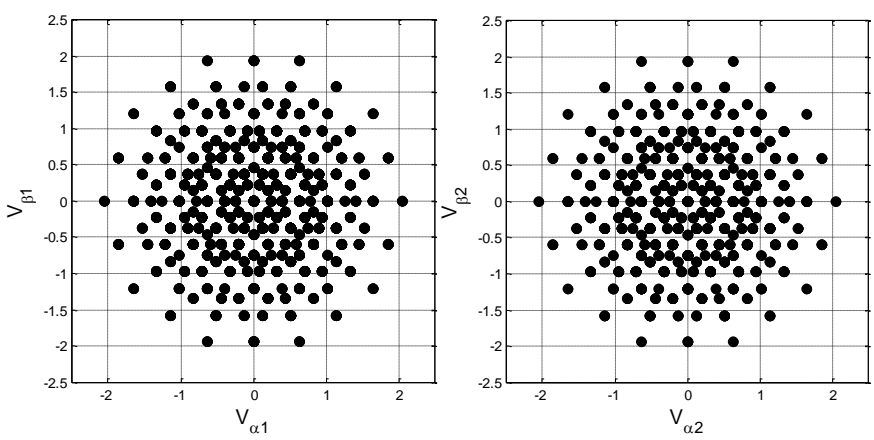

Fig. 2: Voltage vectors in the stator reference frame (normalized by Vdc).

Left: Subspace associated with the fundamental component (a). Right: Subspace associated with the third-harmonic component (b).

\section{DRIVE MODELING}

The topology under study is Fig. 1, which consists of two isolated voltage sources, two five-leg inverters and a five-phase open-end winding PMSM.

Assuming no magnetic saturation and no saliency, the voltage equations are given by:

$$
\left[\begin{array}{c}
V_{a} \\
V_{b} \\
V_{c} \\
V_{d} \\
V_{e}
\end{array}\right]=R_{s}\left[\begin{array}{c}
I_{a} \\
I_{b} \\
I_{c} \\
I_{d} \\
I_{e}
\end{array}\right]+\left[\begin{array}{ccccc}
L_{1} & M_{1} & M_{2} & M_{2} & M_{1} \\
M_{1} & L_{1} & M_{1} & M_{2} & M_{2} \\
M_{2} & M_{1} & L_{1} & M_{1} & M_{2} \\
M_{2} & M_{2} & M_{1} & L_{1} & M_{1} \\
M_{1} & M_{2} & M_{2} & M_{1} & L
\end{array}\right] d\left[\begin{array}{c}
I_{a} \\
I_{b} \\
I_{c} \\
I_{d} \\
I_{c}
\end{array}\right]+\left[\begin{array}{c}
E_{a} \\
E_{b} \\
E_{c} \\
E_{d} \\
E_{e}
\end{array}\right]
$$

with $R_{s}$ the stator resistance, $L, M_{1}$ and $M_{2}$ the stator self and mutual inductances, $I_{x}$ the $x$-phase current, $E_{x}$ the electromotive force (emf) induced by the permanent magnets in the $\mathrm{x}$-phase and $\mathrm{V}_{\mathrm{x}}$ the voltage at the $\mathrm{x}$-phase terminals ( $\mathrm{x} C$ $\{a, b, c, d, e\})$. The negative DC bus of inverter 1 is chosen as voltage reference for inverter 1 , while the negative bus of inverter 2 is chosen as voltage reference for inverter 2 . Hence:

$$
\mathrm{V}_{\mathrm{x}}=\mathrm{V}_{\mathrm{x} 1}-\mathrm{V}_{\mathrm{x} 2}-\mathrm{V}_{21}
$$

where $V_{21}$ is the voltage difference between the negative bus of inverter 2 and the negative bus of inverter 1 .

As there is no zero-sequence path for the current, the sum of the phase currents is equal to zero:

$$
I_{a}+I_{b}+I_{c}+I_{d}+I_{e}=0
$$

Applying the Concordia and Park transformations to the equations (1), the modeling of the system expressed in the stator and rotor reference frame is obtained, with notations $\alpha_{1} \beta_{1} \alpha_{2} \beta_{2} 0$ and $\mathrm{d}_{1} \mathrm{q}_{1} \mathrm{~d}_{2} \mathrm{q}_{2} 0$ respectively. The zero-sequence voltage component is calculated as follows:

$$
\mathrm{V}_{0}=\frac{1}{\sqrt{5}}\left(\mathrm{~V}_{\mathrm{a}}+\mathrm{V}_{\mathrm{b}}+\mathrm{V}_{\mathrm{c}}+\mathrm{V}_{\mathrm{d}}+\mathrm{V}_{\mathrm{e}}\right)
$$

Substituting (1), and (3) into (4) yields:

$$
\mathrm{V}_{0}=\mathrm{E}_{0}
$$

where $E_{0}$ is the zero-sequence of the back emf and can be calculated as the same way of Eq. (4).
An analytical expression of $\mathrm{V}_{21}$ is obtained by substituting (2) into (1) and calculating the zero-sequence component:

$$
\mathrm{V}_{21}=\frac{1}{\sqrt{5}} \mathrm{~V}_{0, \text { eq }}-\frac{1}{\sqrt{5}} \mathrm{E}_{0}
$$

with $\mathrm{V}_{0 \text {,eq }}$ the zero-sequence voltage of an equivalent inverter which would have a connexion between the two negative DCbus. That is:

$$
\mathrm{V}_{0, \mathrm{eq}}=\frac{1}{\sqrt{5}}\left(\mathrm{~V}_{\mathrm{a} 1}+\mathrm{V}_{\mathrm{b} 1}+\mathrm{V}_{\mathrm{c} 1}+\mathrm{V}_{\mathrm{d} 1}+\mathrm{V}_{\mathrm{e} 1}-\mathrm{V}_{\mathrm{a} 2}-\mathrm{V}_{\mathrm{b} 2}-\mathrm{V}_{\mathrm{c} 2}-\mathrm{V}_{\mathrm{d} 2}-\mathrm{V}_{\mathrm{e} 2}\right)
$$

Eq. (7) shows that $V_{0, \text { eq }}$ depends on the instantaneous output voltage of the inverter. Practically, $\mathrm{V}_{0, \mathrm{eq}}$ is thus a control variable, whereas $\mathrm{V}_{0}$ has no interest for control purpose.

It is worth noticing that (6) is similar to the expression obtained for a star connection [12]. With a star connection, the neutral-point floating voltage is affected by the zero-sequence emf and inverter output voltage, while for the topology under study it is $\mathrm{V}_{21}$.

As $\mathrm{V}_{21}$ is associated with the zero-sequence component, it has no effect on the $\alpha \beta$ components and the space vector theory can be applied by omitting $\mathrm{V}_{21}$ in the calculation of these components.

For the topology under study, the inverter has $2^{10}$ different combinations of states. The corresponding vectors are depicted in Fig. 2 (a) and (b) for the subspaces associated with the fundamental $\left(\alpha_{1} \beta_{1}\right)$ and third-harmonic $\left(\alpha_{2} \beta_{2}\right)$ components respectively.

The electromagnetic torque of the PMSM is given by:

$$
\mathrm{T}_{\mathrm{em}}=\mathrm{e}_{\mathrm{a}} \mathrm{I}_{\mathrm{a}}+\mathrm{e}_{\mathrm{b}} \mathrm{I}_{\mathrm{b}}+\mathrm{e}_{\mathrm{c}} \mathrm{I}_{\mathrm{c}}+\mathrm{e}_{\mathrm{d}} \mathrm{I}_{\mathrm{d}}+\mathrm{e}_{\mathrm{e}} \mathrm{I}_{\mathrm{e}}
$$

with $\mathrm{e}_{\mathrm{x}}=\mathrm{E}_{\mathrm{x}} / \Omega$ and $\Omega$ the mechanical speed.

\section{CONTROL STRATEGY}

This section describes the control strategy used for the experimental tests. First, the modulation strategy is briefly described. This modulation strategy is common to all control schemes (healthy and faulty). No modification of this strategy is required for the post-fault operation.

Next, the control strategy in healthy operation is briefly addressed, followed by the control strategies with an opencircuit fault and an inverter-switch short-circuit fault.

\section{A. Modulation strategy}

A very simple modulation strategy is chosen for this application, i.e. a centered PWM strategy with the duty cycles $\delta_{\mathrm{x}, 1}$ and $\delta_{\mathrm{x}, 2}$ calculated as follows (x $\left.C\{\mathrm{a}, \mathrm{b}, \mathrm{c}, \mathrm{d}, \mathrm{e}\}\right)$ :

$$
\begin{gathered}
\delta_{\mathrm{x}, 1}=\frac{1}{2}\left(\frac{\mathrm{V}_{\mathrm{x}}^{*}}{\mathrm{~V}_{\mathrm{DC}}}+1\right) \\
\delta_{\mathrm{x}, 2}=\frac{1}{2}\left(-\frac{\mathrm{V}_{\mathrm{x}}^{*}}{\mathrm{~V}_{\mathrm{DC}}}+1\right)=1-\delta_{\mathrm{x}, 1}
\end{gathered}
$$

with $\mathrm{V}_{\mathrm{x}}{ }^{*}$ the voltage reference of the $\mathrm{x}$-phase $\left(-\mathrm{V}_{\mathrm{dc}} \leq \mathrm{V}_{\mathrm{x}}{ }^{*} \leq \mathrm{V}_{\mathrm{dc}}\right)$. 


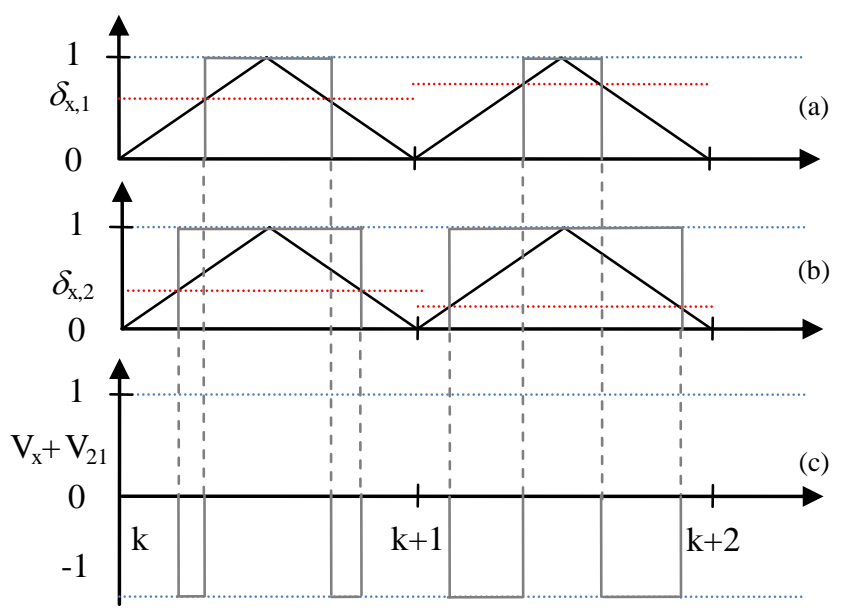

Fig. 3: Carrier-based modulation strategy. (a) Switching function of the x1leg. (b) Switching function of the x2-leg. (c) Voltage at the x-phase terminals (normalized by $\mathrm{Vdc}$ ).

An example is given in Fig. 3, showing the modulation functions, the triangular carrier and the resulting voltage of the $\mathrm{x}$-phase.

\section{B. Control strategy in healthy operation}

Fig. 4 shows the general scheme for torque control. To keep the control scheme simple, the calculation of the current references is obtained from the torque reference and the fundamental component of the back-emf. In the Park reference frame, we have:

$$
\left\{\begin{array}{l}
\mathrm{I}_{\mathrm{d} 1}^{*}=0 \\
\mathrm{I}_{\mathrm{q} 1}^{*}=\frac{\mathrm{T}_{\mathrm{em}}^{*}}{\mathrm{e}_{\mathrm{q} 1}} \\
\mathrm{I}_{\mathrm{d} 2}^{*}=0 \\
\mathrm{I}_{\mathrm{q} 2}^{*}=0
\end{array}\right.
$$

Proportional integral (PI) controllers are used for the current control, along with an emf feedforward compensation.

The zero-sequence voltage can be chosen in order to increase the DC-link voltage utilization by injecting voltage harmonic components which are multiple of five. However, the choice in this paper is to maintain the average value of $\mathrm{V}_{21}=0$ (healthy operation). Therefore, from (6), the zerosequence voltage of the equivalent inverter is given by:

$$
\mathrm{V}_{0, \mathrm{eq}, \mathrm{H}_{0}}^{*}=\mathrm{E}_{0}
$$

where $\mathrm{H}_{0}$ is a subscript which refers to the healthy operation.

\section{Control strategy with a short-circuit fault (inverter switch)}

It is much more interesting to deal with a shorted switch fault with the topology under study. Under the fault condition, it is assumed that the complementary switch is blocked open in order to avoid a short-circuit of the associated DC source.
Under this fault condition, the number of switch combinations decreases to $2^{9}=512$. It is however difficult to develop a post -fault strategy considering a specific subset of

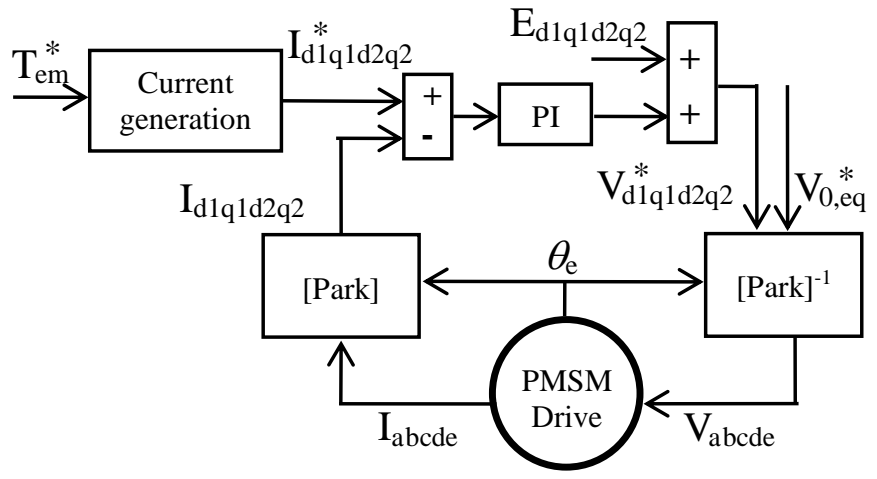

Fig. 4: Control block diagram

vectors and a simple modulation strategy. Therefore, three reconfiguration techniques are investigated in the following sections.

1) Without reconfiguration: similarly to the open-circuit case, it might be interesting to test the fault-tolerant capability of the drive without any change of the control algorithms and modulation strategies.

The main problem in this case is that the converter output voltage is different from the controller reference voltage. As one leg is connected permanently to the positive or negative bus, a voltage DC component appears at the faulty-phase terminals. The controller will try to reject this component (which is rotating at the electrical frequency in the rotor reference frames) and therefore the response depends on the controller and machine parameters. However, injecting a voltage DC component yields a current that is only limited by the stator resistance. Hence, large currents are expected.

2) With a simple reconfiguration: in order to mitigate the fault effects, a simple reconfiguration is achieved by connecting both inverter legs to the positive or negative bus, as shown in Fig. 5. This can be implemented hardware (error signal and additional logic drive the gate signals of the other leg) or software (duty cycle equal to one or zero).

The advantage of this strategy is that the average value of $\mathrm{V}_{\mathrm{x}}$ is equal to zero and there is thus no DC component to be rejected by the controller. On the other hand, there is still a difference between the reference voltage and the inverter output voltage. The drive response is thus again dependent on the controller and machine parameters.

3) With full reconfiguration: to mitigate the aforementioned problem, the controller has to impose a voltage reference which can be generated by the inverter. To do so, the reconfiguration of Fig. 5 applies as well. However, an additional change in the control scheme is mandatory.

Considering Fig. 5 and (2) and assuming the faulty phase is the a-phase, an important and simple result is:

$$
\mathrm{V}_{\mathrm{a}}=-\mathrm{V}_{21}
$$


Eq. (13) shows that the faulty-phase voltage is equal to the voltage difference between the two inverter DC-links.

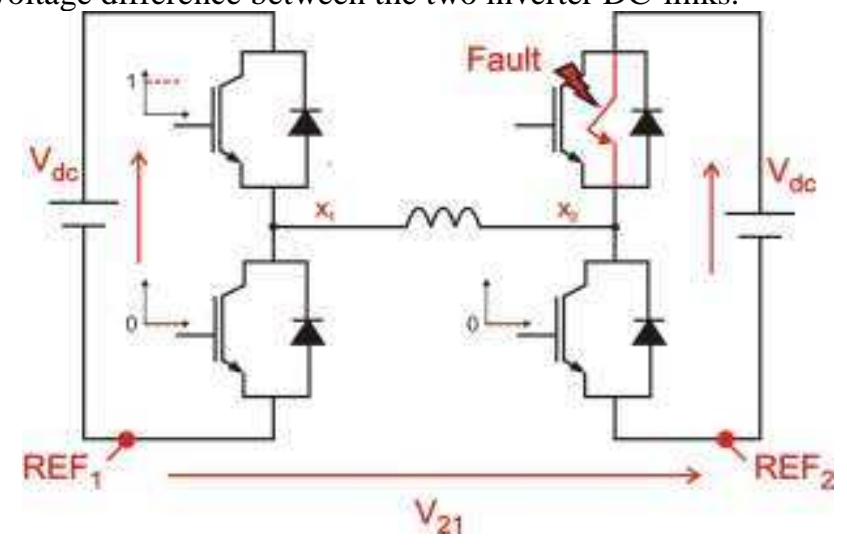

Fig. 5: Reconfiguration of the inverter legs in case of inverter short-circuit fault (top switch of the $\mathrm{x} 2-\mathrm{leg}$ ).

From (6), this voltage can be controlled with the zerosequence voltage of the equivalent inverter.

The Concordia transformation has the following expression:

$\left[\begin{array}{c}\mathrm{V}_{\mathrm{a}} \\ \mathrm{V}_{\mathrm{b}} \\ \mathrm{V}_{\mathrm{c}} \\ \mathrm{V}_{\mathrm{d}} \\ \mathrm{V}_{\mathrm{e}}\end{array}\right]=\sqrt{2 / 5}\left[\begin{array}{ccccc}1 / \sqrt{2} & 1 & 0 & 1 & 0 \\ 1 / \sqrt{2} & \cos (2 \pi / 5) & \sin (2 \pi / 5) & \cos (4 \pi / 5) & \sin (4 \pi / 5) \\ 1 / \sqrt{2} & \cos (4 \pi / 5) & \sin (4 \pi / 5) & \cos (8 \pi / 5) & \cos (8 \pi / 5) \\ 1 / \sqrt{2} & \cos (6 \pi / 5) & \sin (6 \pi / 5) & \cos (12 \pi / 5) & \cos (12 \pi / 5) \\ 1 / \sqrt{2} & \cos (8 \pi / 5) & \sin (8 \pi / 5) & \cos (16 \pi / 5) & \cos (16 \pi / 5)\end{array}\right]\left[\begin{array}{c}\mathrm{V}_{0} \\ \mathrm{~V}_{\alpha 1} \\ \mathrm{~V}_{\beta 1} \\ \mathrm{~V}_{\alpha 2} \\ \mathrm{~V}_{\beta 2}\end{array}\right]$

and substituting (13) and (6) into (14) yields:

$$
\mathrm{V}_{0, \mathrm{eq}, \mathrm{SC}_{\mathrm{a}}}=-\sqrt{2} \mathrm{~V}_{\alpha 1}-\sqrt{2} \mathrm{~V}_{\alpha 2}
$$

As the objective is to maintain a constant torque, i.e. no modifications of the $\mathrm{d}_{1} \mathrm{q}_{1} \mathrm{~d}_{2} \mathrm{q}_{2}$ currents (or equivalently the $\alpha_{1} \beta_{1} \alpha_{2} \beta_{2}$ currents), the $\mathrm{d}_{1} \mathrm{q}_{1} \mathrm{~d}_{2} \mathrm{q}_{2}$ voltages (or equivalently the $\alpha_{1} \beta_{1} \alpha_{2} \beta_{2}$ voltages) have to be maintained as well. Eq. (15) shows that a modification of the zero-sequence voltage allows this condition to be obtained.

It is worth noticing that the calculation for other phases is immediate.

D. Summary of the control algorithms

A summary of the reconfiguration modes for the cases under study is given in TABLE I.

TABLE I. SUMMARY OF THE CONTROL PARAMETERS FOR THE VARIOUS RECONFIGURATION MODES UNDER STUDY (A-PHASE FAULT)

\begin{tabular}{|c|c|c|}
\hline Mode of operation & $\mathrm{V}_{\mathrm{x}, 1}=\mathrm{V}_{\mathrm{x}, 2}$ & $\mathrm{~V}_{0, \mathrm{eq}}$ \\
\hline Healthy $\left(\mathrm{H}_{0}\right)$ & no & $\mathrm{E}_{0}$ \\
\hline Open-circuit & no & $\mathrm{E}_{0}$ \\
\hline $\begin{array}{c}\text { Short-circuit and no } \\
\text { reconfiguration }\end{array}$ & no & $\mathrm{E}_{0}$ \\
\hline $\begin{array}{c}\text { Short-circuit and simple } \\
\text { reconfiguration }\end{array}$ & yes & $\mathrm{E}_{0}$ \\
\hline
\end{tabular}

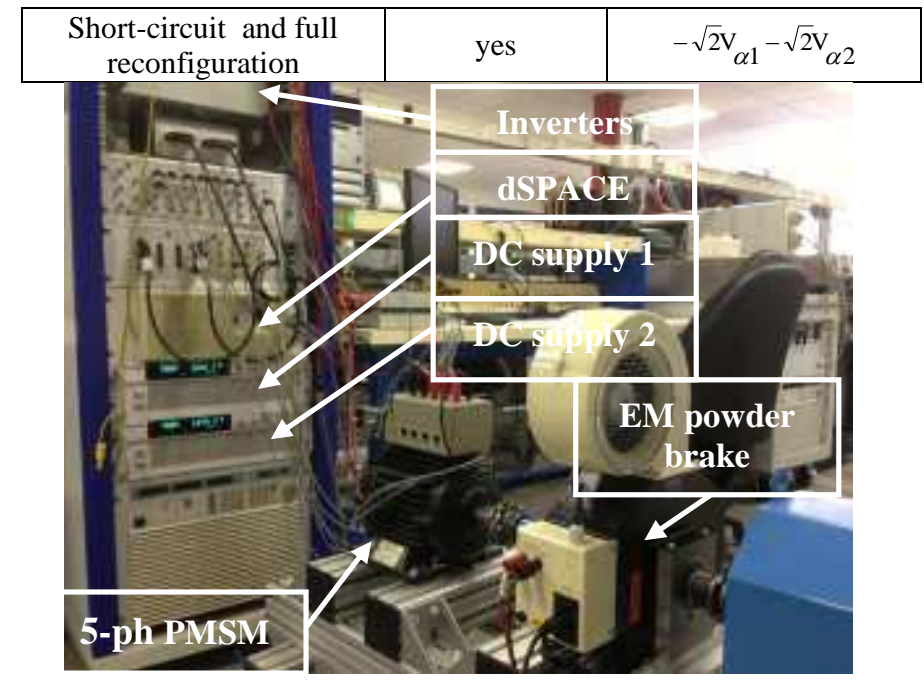

Fig. 6: Experimental platform.

TABLE I. MACHINE PARAMETERS

\begin{tabular}{|c|c|}
\hline Parameters & Values \\
\hline $\mathrm{R}_{\mathrm{s}}$ & $2.24 \Omega$ \\
\hline $\mathrm{L}_{\mathrm{d} 1}=\mathrm{L}_{\mathrm{q} 1}$ & $3.2 \mathrm{mH}$ \\
\hline $\mathrm{L}_{\mathrm{d} 3}=\mathrm{L}_{\mathrm{q} 3}$ & $0.9 \mathrm{mH}$ \\
\hline $\mathrm{e}_{\mathrm{q} 1}$ & $0.51 \mathrm{Vs} \mathrm{rad}^{-1}$ \\
\hline Pole pairs number $\left(\mathrm{N}_{\mathrm{pp}}\right)$ & 2 \\
\hline Nominal speed & $1500 \mathrm{rpm}$ \\
\hline Nominal current & $15 \mathrm{~A}$ \\
\hline Maximum torque & $20 \mathrm{Nm}$ \\
\hline Nominal power & $3.1 \mathrm{KW}$ \\
\hline
\end{tabular}

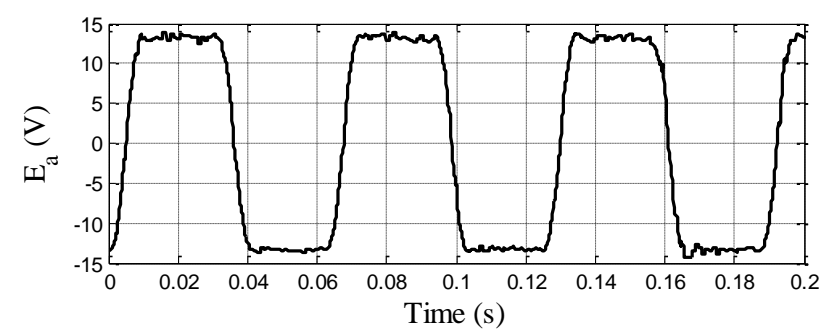

Fig. 7: EMF of the five-phase machine at $\Omega=50 \mathrm{rad} \mathrm{s}-1$.

\section{EXPERIMENTAL RESULTS}

\section{A. Test-bed description}

A picture of the test bed is shown in Fig. 6. The system consists of a five-phase double-ended PMSM, two five-leg inverters and two isolated DC-sources. A dSPACE1005 board is used for control prototyping. The load is an electromagnetic powder brake.

The open-circuit fault is emulated by disconnecting a phase terminal, while a switch short-circuit fault is emulated by setting the corresponding duty cycle to one or zero. 
The machine parameters are given in TABLE I. The emf waveform is almost trapezoidal, as shown in Fig. 7.
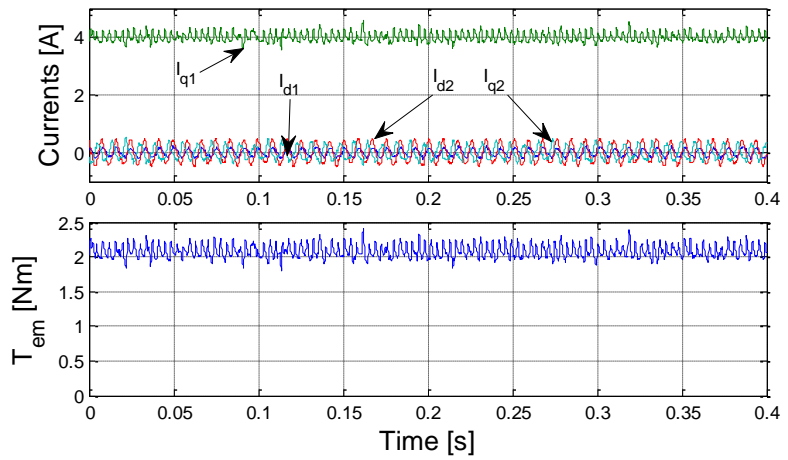

Fig. 8: Healthy operation (experimental results). Top: current expressed in the rotor reference frame. Bottom: Electromagnetic torque (calculated from the model).

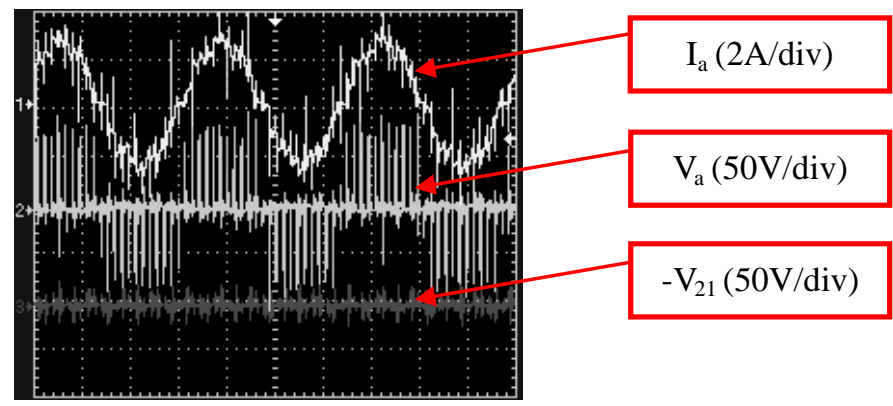

Fig. 9: Healthy operation. Scope results showing the a-phase current $I_{a}$, the aphase voltage $V_{a}$ and the voltage between the two inverter DC-bus $V_{21}$.

\section{B. Control in healthy operation}

Fig. 8 and Fig. 9 show experimental results of the control in healthy operation $(\Omega=38 \mathrm{rad} / \mathrm{s})$. Fig. 8 shows the $\mathrm{d}_{1} \mathrm{q}_{1} \mathrm{~d}_{2} \mathrm{q}_{2}$ currents and the resulting electromagnetic torque (estimated with the model). Fig. 9 shows scope results for the same test presented in Fig. 8. The phase current $I_{a}$ is sinusoidal, lagging the phase voltage $\mathrm{V}_{\mathrm{a}}$. The voltage difference between the two inverter DC-links $V_{21}$ is also measured. It can be seen that $V_{21}$ is close to zero (average and instantaneous values), as expected from the control algorithm in healthy operation.

\section{Control with an inverter short-circuit fault}

1) No reconfiguration: Fig. 10 and Fig. 11 show experimental results of the control with an inverter switch short-circuit fault and no reconfiguration $(\Omega=42 \mathrm{rad} / \mathrm{s})$. The fault occurs at time $\mathrm{t}=0.2 \mathrm{~s}$.

Fig. 10 shows that the current magnitudes in the $d_{2} q_{2}$ subspace increase a lot upon the fault occurrence. Torque ripple of about $165 \%$ appears due to the fault. Fig. 11 shows scope results for the same test. The faulty-phase current $I_{a}$ has a positive DC component, while $\mathrm{V}_{\mathrm{a}}$ and $\mathrm{V}_{21}$ are seriously affected by the fault.

2) Simple reconfiguration: Fig. 12 and Fig. 13 show experimental results of the control with an inverter switch short-circuit fault and simple reconfiguration $(\Omega=40 \mathrm{rad} / \mathrm{s})$. The fault occurs at time $\mathrm{t}=0.2 \mathrm{~s}$. Torque ripple of about $75 \%$ appears due to the fault. The scope results of Fig. 13 shows that the faulty-phase current is quite distorded, but its magnitude is rather low. It can be noticed that this fault induces the supply ( $\mathrm{I}_{\mathrm{d} 2}$ and $\mathrm{I}_{\mathrm{q} 2}$ are different to zero) of the

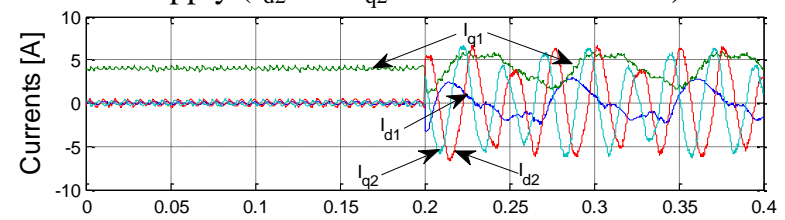

3)

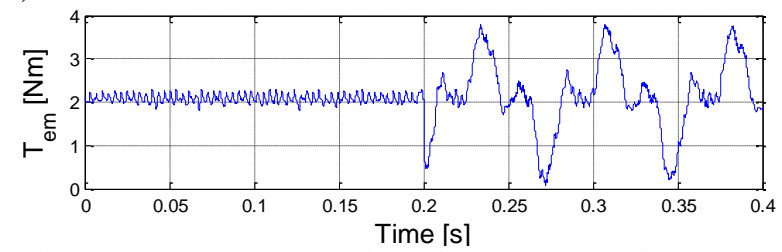

Fig. 10: Inverter switch short-circuit fault and no reconfiguration (experimental results). Top: current expressed in the rotor reference frame.

Bottom: Electromagnetic torque (calculated from the model).

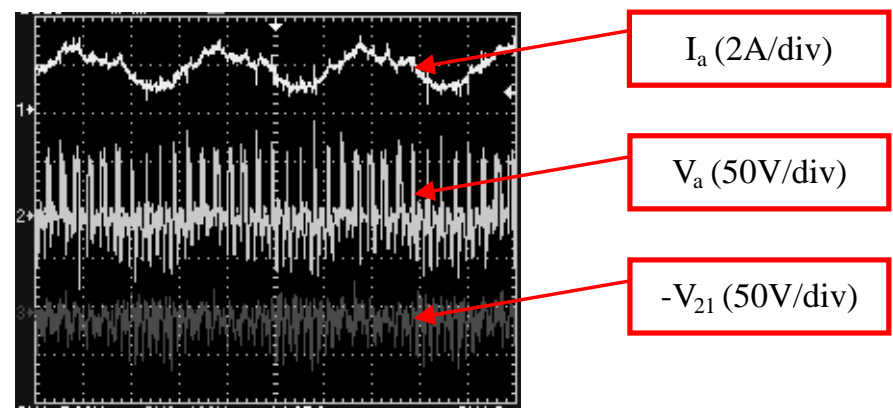

Fig. 11: Inverter switch short-circuit fault and no reconfiguration. Scope results showing the faulty phase current $I_{a}$, the a-phase voltage $V_{a}$ and the voltage between the two inverter DC-bus $V_{21}$.

secondary machine associated with the subspace $\alpha_{2} \beta_{2}$. So in order to obtain a constant torque, we have to use a new reference of currents (voltages) for the two fictitious machines in Concordia reference frame. We can see that when a fault occurs in the inverter, a simple reconfiguration of switches is not enough to obtain a good result in torque control. It can be noticed that the torque ripple is reduced by comparing to Fig. 10 but this value of torque pulsation remains important.

3) Full reconfiguration:. Fig. 14 and Fig. 15 show experimental results of the control with an inverter switch short-circuit fault and full reconfiguration $(\Omega=42 \mathrm{rad} / \mathrm{s})$. The fault occurs at time $t=0.2 \mathrm{~s}$. In this case, torque ripple is of the same quantity as in healthy operation. The faulty-phase current is not distorted (see Fig. 15) and Eq. (13) is verified as $\mathrm{V}_{\mathrm{a}}=-\mathrm{V}_{21}$. By imposing this constraint, the new reference of voltages (for 4 healthy phases) are redetermined. Indeed, in this case, the voltage of phase $b$ is a line-line voltage $\mathrm{V}_{\mathrm{b}^{-}}$ $\mathrm{V}_{\mathrm{a}}=\mathrm{V}_{\mathrm{ba}}$. In the same way, the voltages of three others phases $\left(c, d\right.$ e) are: $V_{\text {ca }}, V_{\text {da }}, V_{\text {ea. }}$. It means that after fault occurrence, the inverter is controlled to obtain the line voltages for compensating the phase a is faulty. Finally, the phase currents of machine are not distorted and maintained as before the fault. 


\section{CONCLUSION}

The paper has analyzed the behavior of an open-end fivephase PMSM drive under inverter fault conditions. With a dual-inverter supply, the equivalent five-phase topology offers

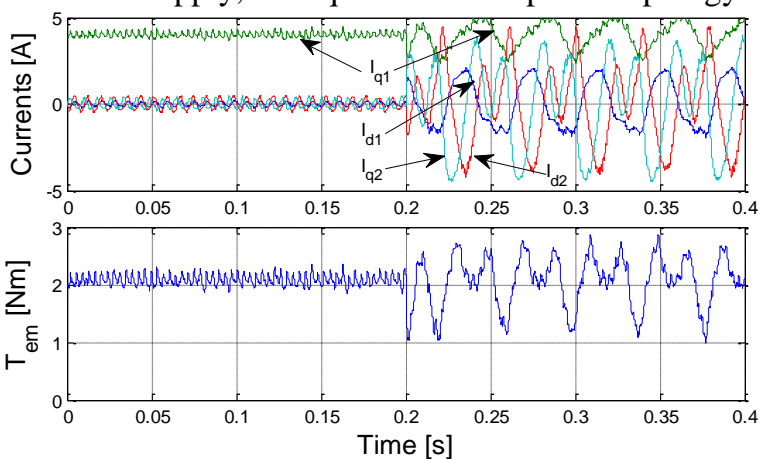

Fig. 12: Inverter switch short-circuit fault and simple reconfiguration (experimental results). Top: current expressed in the rotor reference frame.

Bottom: Electromagnetic torque (calculated from the model).

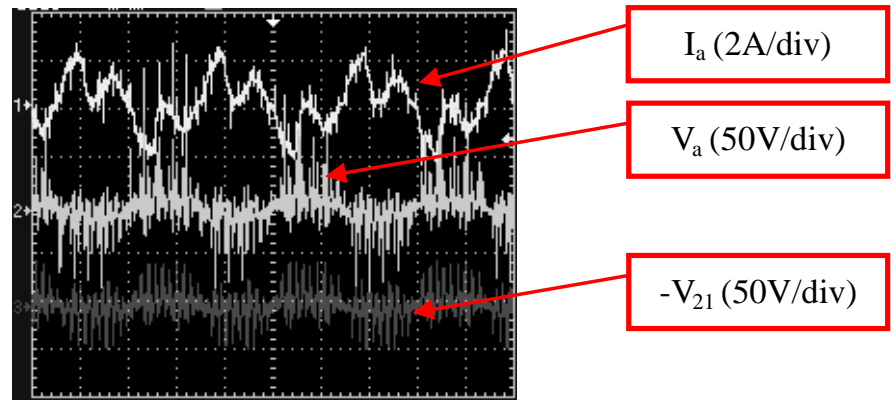

Fig. 13: Inverter switch short-circuit fault and simple reconfiguration. Scope results showing the faulty phase current $I_{a}$, the a-phase voltage $V_{a}$ and the voltage between the two inverter DC-bus $\mathrm{V}_{21}$.

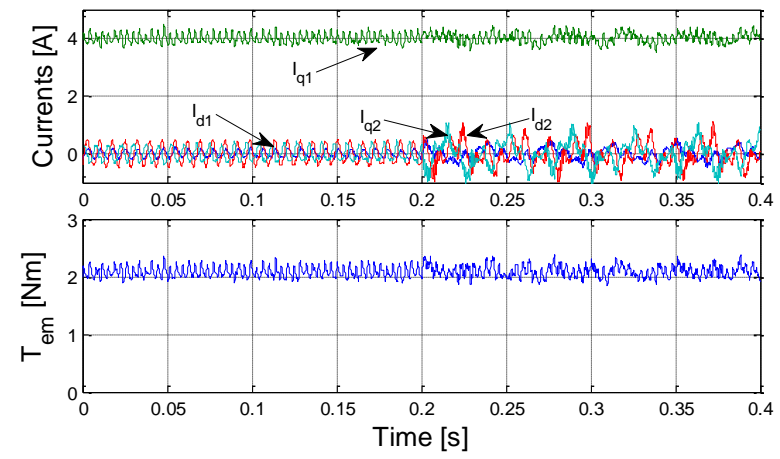

Fig. 14: Inverter switch short-circuit fault and full reconfiguration (experimental results). Top: current expressed in the rotor reference frame. Bottom: Electromagnetic torque (calculated from the model).

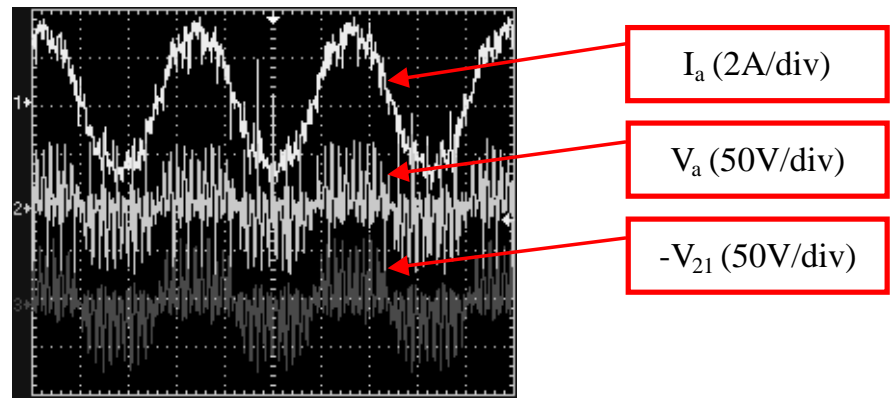

Fig. 15: Inverter switch short-circuit fault and full reconfiguration. Scope results showing the faulty phase current $I_{a}$, the a-phase voltage $V_{a}$ and the voltage between the two inverter DC-bus $\mathrm{V}_{21}$. the possibility to operate the machine under open-circuit and inverter switch short-circuit faults (without additional component). An inherent fault tolerance has been shown in the study. It has also been shown that a simple reconfiguration allows the drive to be operated with the same torque performance as in healthy operation.

\section{ACKNOWLEDGMENT}

The authors would like to thank the ADEME for the funding of the MHYGALE project.

\section{REFERENCES}

[1] Shaoyong Yang; Dawei Xiang; A. Bryant, P. Mawby, L. Ran, and P. Tavner, "Condition Monitoring for Device Reliability in Power Electronic Converters: A Review," IEEE Trans. on Power Electronics, vol.25, no.11, pp.2734-2752, Nov. 2010.

[2] B.A. Welchko, T.A. Lipo, T.M. Jahns, and S.E. Schulz, "Fault tolerant three-phase ac motor drive topologies; a comparison of features, cost, and limitations," IEEE Trans. on Power Electronics, vol. 19, no. 4, pp. 1108-1116, 2004

[3] R.R. Errabelli and P. Mutschler, "Fault-Tolerant Voltage Source Inverter for Permanent Magnet Drives," IEEE Trans. on Power Electronics, vol.27, no.2, pp.500-508, Feb. 2012

[4] M. Naidu, S. Gopalakrishnan, T.W. Nehl, "Fault-Tolerant Permanent Magnet Motor Drive Topologies for Automotive X-By-Wire Systems," IEEE Trans. on Industry Applications, vol.46, no.2, pp.841-848, 2010.

[5] F. Richardeau, Zhifeng Dou; J.-M. Blaquiere, E. Sarraute, D. Flumian, and F. Mosser, "Complete short-circuit failure mode properties and comparison based on IGBT standard packaging. Application to new fault-tolerant inverter and interleaved chopper with reduced parts count," 14th European Conference on Power Electronics and Applications (EPE 2011), pp.1-9, 2011

[6] Y. Wang, T.A. Lipo, and D. Pan, "Robust operation of double-output AC machine drive," IEEE 8th International Conference on Power Electronics and ECCE Asia (ICPE \& ECCE), pp.140-144, 2011.

[7] B.C. Mecrow, A.G. Jack, J.A. Haylock, and J. Coles, "Fault-tolerant permanent magnet machine drives," in Electric Power Applications, IEE Proceedings-, 1996, vol. 143, no. 6, pp. 437-442.

[8] A.M. El-Refaie, "Fault-tolerant permanent magnet machines: a review," Electric Power Applications, IET, vol.5, no.1, pp.59-74, January 2011

[9] Jingwei Zhu; Xiaobing Niu, "Investigation of short-circuit fault in a fault-tolerant brushless permanent magnet AC motor drive with redundancy," IEEE Conference on Industrial Electronics and Applications (ICIEA), pp.1238-1242, 15-17 June 2010.

[10] L. Parsa, "On advantages of multi-phase machines," in 31st Annual Conference of IEEE Industrial Electronics Society (IECON 2005), 2005.

[11] F. Meinguet, P. Sandulescu; X. Kestelyn and E. Semail, "A Method for Fault Detection and Isolation Based on the Processing of Multiple Diagnostic Indices: Application to Inverter Faults in AC Drives," IEEE Trans. on Vehicular Technology, vol.62, no.3, pp.995-1009, 2013.

[12] F. Meinguet, E. Semail, and J. Gyselinck, "An on-line method for stator fault detection in multi-phase PMSM drives," in Vehicle Power and Propulsion Conference (VPPC), 2010 IEEE, pp. 1-6.

[13] X. Kestelyn, and E. Semail, "A Vectorial Approach for Generation of Optimal Current References for Multiphase Permanent-Magnet Synchronous Machines in Real Time," IEEE Trans. on Industrial Electronics, vol.58, no.11, pp.5057-5065, Nov. 2011.

[14] N. Bianchi, S. Bolognani; and M.D. Pre, "Design and Tests of a FaultTolerant Five-phase Permanent Magnet Motor," in 37th IEEE Power Electronics Specialists Conference (PESC '06), pp.1-8, June 2006.

[15] D. Flieller, N.K. Nguyen, P. Wira, G. Sturtzer, D. Abdeslam, and J. Merckle, "A Self-Learning Solution for Torque Ripple Reduction for Non-Sinusoidal Permanent Magnet Motor Drives Based on Artificial Neural Networks," IEEE Trans. on Industrial Electronics, Avril 2013.

[16] A. Tani, M. Mengoni, M.; L. Zarri, G. Serra and D. Casadei, "Control of Multiphase Induction Motors With an Odd Number of Phases Under Open-Circuit Phase Faults," IEEE Trans. on Power Electronics, vol.27, no.2, pp.565-577, Feb. 2012. 
[17] E. Levi, I.N.W. Satiawan; N. Bodo and M. Jones, "A Space-Vector Modulation Scheme for Multilevel Open-End Winding Five-Phase Drives," IEEE Trans. on Energy Conversion, vol.27, no.1, pp.1-10, 2012. 